\title{
The Development of Emotional Intelligence by Means of Art
}

\author{
Maxim Kozhemyakin ${ }^{1, a *}$ \\ 1 Immanuel Kant Baltic Federal University, 236016, 14 A. Nevskogo str., Kaliningrad, Russia \\ amaxim.kozhemyakin@gmail.com \\ ${ }^{*}$ Corresponding author
}

Keywords: emotional intelligence, psychology of art, liberal education, emotional development

\begin{abstract}
The article provides an overview of scientific approaches to the problem of emotional intelligence and ways of its development. The focus is on the experience of research in this field, including Russian and foreign psychologists and educators. The pedagogical and developmental potential of art in the formation of emotional intelligence is demonstrated by examples of the use of music and literature in specially organized developing conditions. It also provides analytical data revealing the connection between education in the arts and career success, which once again problematizes the "tilt" towards technical education to the detriment of the humanities in education systems, which is characteristic not only Russian but also foreign ones.
\end{abstract}

\section{Introduction}

Both topics indicated in the title of the article have become extremely relevant in recent decades, and at the same time, often being discussed separately, they yet implicitly contain one another. Emotional intelligence is traditionally discussed by professional psychologists, D. V. Lyusin, I. N. Andreeva, D. V. Ushakov, P. Salovey, J. Mayer, and others, as well as authors of near-scientific sense, such as, for example, D. Goleman or T. Bradbury. The place of art in the education system, both secondary and higher, is most acutely problematic among theorists of the liberal education system (see the works of M. Nussbaum and M. Epstein, for instance).

Studies on emotional intelligence, including the significance of this phenomenon in education and in a professional career, are gradually crowding out the study of general intelligence, as well as social intelligence, and one can find evidence by the dynamics of the number of publications in these areas [8]. At the same time, Peter Salovey and John Mayer, who proposed the concept of emotional intelligence in 1990, considered it a social form [8]. In 1995, the famous book by D. Goleman was published, which contained a number of bold statements regarding the exceptional influence on the vital success of emotional intelligence, but these statements were not supported by further scientific research. In other words, the problem of emotional intelligence today has a number of serious methodological issues related to the status of this phenomenon, and its measurement capabilities, as well as predictive capabilities. If the picture is clear and almost obvious with general intelligence and career success, as well as with success in learning, then there is no such unambiguity with emotional intelligence. For instance, studies in the spirit of D. Goleman speak of emotional intelligence as almost the leading factor of success in life (although here immediately there is a mass of methodological questions about the assessment of this very success and to the subject of its application, which is "life"). On the other hand, less optimistic academic studies give us more restrained results. But indisputable is what makes us every day. People able to recognize their emotions, emotions of others are more able to manage them (not control, namely manage). Respectively, they control themselves in difficult life situations, which, ultimately, allows them to be more environmentally friendly in relation to their mental resources in solving psychologically difficult tasks. And the latter is already connected with the subjective quality of life.

\section{Methodology}

In this article, we attempt to present the main directions of research, both foreign and Russian, devoted to the question of the place of art in the education system, as well as its pedagogical and "psychotechnical" potential in the development of emotional intelligence. As a result, we hope to mark the further trajectory of empirical and applied research in the field of Psychology of Emotional Intelligence and the Psychology of 
Art.

\section{Research}

Emotions can be collectively defined as states associated with the assessment of the significance for an individual of factors acting on him and expressed primarily in the form of direct experiences of satisfying or not satisfying his actual needs. They are one of the main regulators of activity. There are quite a few definitions of emotional intelligence for today, but D. V. Lyusin gives one that is capacious and unifying everything else: the ability to understand their own and others' emotions and their management $[3,8]$.

Thus, an emotional component of everyday life, be it emotional intelligence or emotions in themselves, are if not the leading but an important factor in its assessment. And thus, even at the level of everyday knowledge, we have two things connected: first, developed emotional intelligence allows us to recognize and control emotions, which makes the assessment of a complex situation more cons cious and rational; and secondly, such situations themselves ceasing to have such a devastating impact reinforce the positive experience of applying emotional intelligence to similar situations in the future.

We will not talk about the exceptional importance of emotional intelligence to the detriment of all other forms when evaluating success of a particular activity, nor will we say that the development of emotional intelligence is possible by reading the relevant literature and performing the tasks proposed by its authors. Moreover, we are inclined to assume that the "tuning" of the emotional component of the personality is a much more complicated process than it might seem at first glance, since, apart from psychotechnology, trainings or some other psychological does not have enough influence.

The complexity and multidimensionality of emotional development is well demonstrated by the research conducted by A. V. Zaporozhets, which, of course, is still not talking about emotional intelligence. However, studying the first experience of observing a child's tale characters in a puppet theater, he describes the evolution in the behavior of preschoolers: co-presence, sympathetic co-action, empathy, sympathy and co-experiencing [4, p. 17]. Moreover, there is a moment of co-thought [4], which ultimately reinforces the position of L. S. Vygotsky about the unity of affective and rational in knowledge. If we turn to one of the definitions of emotional intelligence (for example, D. V. Lyusin), according to which emotional intelligence is "a set of abilities for understanding and controlling one's own and other's emotions" [3], then behavioral reactions of preschoolers in the theater (described by A. V. Zaporozhets) are the essence in the manifestation of emotional and intelligence at the pre-reflex stage, when a preschooler does not yet have a focus on himself, but he/she focuses only on the hero whom observes. Simply put, a child has no need to reflect on what is happening to him and what purpose it serves. He just looks, listens, and reacts in some way.

Here it's important that at some point an adult enters this perception of what is happening by the child, playing the role of a kind of conductor on the way of translating the emotional register into a semantic register, for which he uses speech helping to name what the child is experiencing or suggesting hero's emotions. Another fundamentally important point here is the opportunity to place the child in such a situation: theater's auditorium, other children, a meaningful and interesting performance, presence of an adult (on the contrary, its absence), readiness of the child himself to perceive what is happening on stage meaningfully, etc. Of course, we mean any similar situation, such as watching a movie, listening to music, reading a book, a magazine, or a comic book, etc. We mean here not only the physical possibility of such a situation, but also its quality. And finally, we must understand that this kind of conditions for "launching" an emotional response, and, accordingly, the likelihood and nature of "fitting" it into the process of emotional development, depends on many random factors, which are external and internal in relation to the subject.

In other words, the process of developing emotional intelligence is too multifaceted to be reduced to psychological techniques, exercises and training. We see here as appropriate an interdisciplinary approach that allows us to consider the development of emotional intelligence systematically.

Without claiming to exhaust the issue, we consider art as an essential element in the development of emotional intelligence. The reason for this is, first of all, the fact that quite a lot of theoretical and empirical material has been accumulated in the field of research into the influence of various types of art on the 
development of intelligence, on the processes of socialization, emotional sphere, and so on. Second, it does not seem to us accidental that the principle of unity developed by L. S. Vygotsky is most fully revealed in his work "The Psychology of Art", a text interesting not only psychologists, but also in other fields of knowledge, and this interest is growing today. And, third, we continue the tradition of exploring the interaction of man and art, which has it origins in Antiquity.

So, in the book by M. M. Pozdnev titled "Psychology of Art: The teachings of Aristotle", we find a curious reference to Croesus, who advises Cyrus to introduce music education in Lydia in order to avoid the uprising of the Lydians, "They were led to teach children to play stringed instruments and soon, O king, you will see that they have become women from their husbands" [7, p. 204]. Speaking about psychological research, here we, first of all, rely on the already mentioned work written by L. S. Vygotsky "The Psychology of Art". In it we find the following position: “... Art is the most important center of all biological and social processes of the individual in society, ... it is a way to balance a person with the world in the most critical and crucial moments of life" [2, p. 331]. In addition, L. S. Vygotsky calls art "the technique of the senses" [2, p. 309], developing the idea that it initially arises as a means of struggle for existence and then transformes into a means of involvement in social life. Indeed, evoking one or another feeling prompting to action, art carries in itself not a direct message, it is not a text, not a musical notation, pictures that do not replace each other, but something that is "above", as if that side of the work, what we know, feel, and what, ultimately, allows the subject to "stick" into the fabric of social relations.

B. G. Ananyev in the article "Tasks of the psychology of art", partly criticizing the approach of L. S. Vygotsky, notes a crucially important point. He writes, "A person becomes a reader before he learns to read. The mechanism of interiorization in the field of art is often independent of man. A person acts as a spectator, listener throughout his life (for example, thanks to mass media channels)" [1, p. 258]. At first glance, this seems controversial, but in reality any human subject was initially included not just in the society of his own kind, but in the system of signs and symbols, first of all, in speech, through which he masters the culture, including the culture of interaction between people.

Of course, speaking of the methodological aspects of the study of art and its influence on the formation of personality, we cannot do without the ideas of M. M. Bakhtin about "co-being" and the work of art as a subject, which opens up new research opportunities, including in the field of the Psychology of Emotional Intelligence. The psychological consequences of such an understanding of art are considered by $\mathrm{V}$. P. Zinchenko. Describing the approaches of L. S. Vygotsky, G. G. Shpet, and M. M. Bakhtin have to art as a unique technology of personal development, he focuses our attention on the problem of catharsis, the place of an emotional component in the perception of art, the relationship between man and the work of art [4]. Here the key role is played by the perception of a work of art as a full-fledged subject with which we enter into interaction. Its authorship goes into the background, because the one who perceives (looks, listens, or reads) becomes an author, constructs both the work itself and, what is also important, itself.

What happens in this moment of interaction? And why is research in this area relevant today?

As Irma Ghosn of the Lebanese American University notes, "Today's children lack the ability to empathize, negotiate and cooperate, and they often cannot be optimistic and hopeful about the future. This emptiness has potentially negative consequences, primarily in their academic achievements, and secondly, in interpersonal relationships. These two factors together affect the psychological development of children and can lead to behavioral problems, alienation, and possibly even aggression and violence" [11]. At the same time, having in focus the scientific and practical interest of the problem of migrant children, she sees a partial solution of these problems through the literature, "Carefully selected literature can offer an immigrant child a language of empathy and care in a new language and thus facilitate the recognition and expression of empathic feelings" [11].

Gordon Allport insisted that psychology in general should learn from literature. Namely, that it gives us a description of the most stable personality traits [6], with making use of much richer (than scientific) literary language. G. Allport did not specifically deal with this problem, but we have at our disposal the work of psychologists who, as much as possible, elucidate those special experiences, feelings and emotions contained in the literary work that made them eternal. Accordingly, what professor Gosn says about carefully selected literature can be realized without much difficulty. We have at our disposal the "Tragedy of Hamlet" by L. S. Vygotsky, and "Dostoevsky and patricide" by Z. Freud, and "Black Sun" by Y. 
Kristeva, where there are the works of F. M. Dostoevsky and many other texts.

Thus, in addition to specially organized psychological programs for the development of emotional intelligence, art is actively used and serves here as a development technique.

The book "Not for Profit" by M. Nussbaum describes the experience of building communication among adolescents from disadvantaged areas of New York who sing in the choir. Those who have certain psychological difficulties associated with age-related changes in mental, social, and physiological personality or a way of life, it is necessary for them to appear before a large number of peers and the public in all their immaturity, uncertainty, incompetence, etc., in extremely unusual conditions for themselves, such as singing. In this complex action, adolescents learn empathy, they turn to their emotional experience, as well as the experience of other children [5]. Approximately the same conclusions are drawn by Michelle Kashub from the University of Southern Maine. In particular, he states, "The social interactions required to create music create many opportunities for students to develop their skills in assessing their own feelings and trying to constructively link them with the feelings of others" [12].

In other words, music is a potentially socializing activity that attracts, which is important, not through the need and the system of coercion (like it is in a school or kindergarten), but passionately [10]. In a sense, music is an occupation that is more natural to humans than math or chemistry. At the same time, English philosopher Roger Scruton states, "Through melody, harmony, and rhythm, we enter a world in which there are others besides us, a world that is full of feelings, but also which is also ordered, disciplined, and free. That is why music is a character-forming force" [as cited in 10].

Without focusing on emotional intelligence, simply not using this term, Martha Nussbaum describes the same problems that a modern schoolchild or student faces because of the "bank" towards technical and technological education. At the same time, she draws her and our attention to the role of parental concern when choosing their children's specialty that they want to master. In particular, she states, "Most of those who come from childhood were accustomed to the idea that the goal of education is to get a good job. The idea that it is necessary to study subjects capable of educating a person as an active and thinking citizen of his country never came to such people" [5, p. 168]. This is all the more surprising if we turn to the statistics that Michael Epstein cites, saying that in the UK only $10 \%$ of the total number of members of parliament are educated in the natural sciences, while $65 \%$ are in the humanities and social sciences. The same applies to the American business elite: $60 \%$ here belong to the humanities [9].

The provisions of M. Nussbaum, M. Epstein and probably still a large number of researchers in the field of development and education clearly demonstrate the contradiction that has arisen as a result of the rejection of the affective component in the process of personality development towards the intellectual, the unity of which L. S. Vygotsky insisted. At the same time, employers themselves note that those employees who are able to work in a team, know how to associate professional problems with ethical issues, and have the ability to effectively communicate in both written and oral also have the greatest value [9]. In other words, an emotional component of cognition and activity is becoming increasingly important. Hence, probably, such demand for developments in the field of emotional intelligence is not accidental.

\section{Conclusion}

Of course, we did not pretend to comprehensively present the issues of emotional intelligence, its development through art and the relevance of such works in the education system. We pursued the goal of identifying the contradictions that exist at the junction of these three areas of knowledge, and also briefly present the areas of research that these contradictions seek to resolve. The main conclusions that we can make are as follows. First, when working with such a construct as emotional intelligence, we should distinguish between scientific approaches and near-scientific, which are encouraged but not supported by empirical research. Second, the development of emotional intelligence is possible only in a complex, not just with the use of psychological techniques alone. Third, being understood after L. S. Vygotsky as a technique, art can also not be considered as the only tool for developing emotional intelligence despite its full potential. Fourth, the development of emotional intelligence, on the one hand, can be considered as a component of solving socialization problems, including the individual in social relations, and on the other hand, as a component of successful learning, career building and other achievements related to 
communication and social relations in general.

\section{References}

[1] Ananiev, B. G. (1982). Tasks of the psychology of art: Art creativity. Leningrad.

[2] Vygotsky, L. S. (1968). Psychology of art. Moscow, USSR.

[3] Degtyarev, A. V. (2012). "Emotional Intelligence": The formation of concepts in psychology. Psychological science and education, 2, pp. 23-39.

[4] Zinchenko, V. P. (2006). Psychological aspects of the influence of art on man. Cultural-historical psychology, 4, pp. 3-21.

[5] Nussbaum, M. (2014). Not for Profit: Why democracy needs humanities. Moscow, Russia.

[6] Gippenreiter, Y. B., \& Puzyreya, A. A. (1982). Personality: the problem of science or art? In G. Allport (Ed.), Psychology of Personality (pp. 228-230). Moscow, USSR.

[7] Pozdnev, M. M. (2010). Psychology of art: The teachings of Aristotle. Moscow; St. Petersburg, Russia.

[8] Lyusin, D. V., \& Ushakov, D. V. (Eds.) (2009). Social and emotional intelligence: From processes to measurements. Moscow, Russia.

[9] Epstein, M. (2018). About humanitarian invention. Retrieved from http://www.nlobooks.ru/node/7211.

[10] Ball, Ph. (2010). The music instinct: How music works and why we can't do without it. Oxford, UK.

[11] Ghosn, I. K. (2018). Nurturing emotional intelligence through literature. Retrieved from https://www.researchgate.net/publication/242540340.

[12] Kaschub, M. (2018). Defining Emotional Intelligence in Music Education. Retrieved from https://www.researchgate.net/publication/240538858. 